\title{
Identification of Severely Burnt Bodies Due to Post Collision Fire: Bus - Truck Collision at Induruwa, Southern Sri Lanka
}

Rohan Ruwanpura ${ }^{1 *}$, Muditha Vidanapathirana ${ }^{2}$, Sisira Ranasinghe ${ }^{3}$, Mahinda Hettiarachchi ${ }^{4}$, Janaki Warushahennadi ${ }^{5}$, Sisira Seneviratne $^{5}$, Kumudu Dhahanayaka ${ }^{5}$, Sriyantha Amararatne ${ }^{5}$ and Ruwan Nanayakkara ${ }^{5}$

${ }^{1}$ Consultant Judicial Medical Officer, Teaching Hospital, Karapitiya, Galle, Sri Lanka

${ }^{2}$ Senior Lecturer in Forensic Medicine, Faculty of Medicine, Karapitiya

${ }^{3}$ Forensic Odontologist, Dental Institute, Colombo

${ }^{4}$ Additional Consultant Judicial Medical Officer, Galle

${ }^{5}$ Post Graduate Registrars in Forensic Medicine

\begin{abstract}
Road traffic accidents are one of the well known causes responsible for mass causality incidents in many part of the world. Here, we present a case of bus truck collision resulted in nineteen deaths, where bodies of victims were burnt beyond recognition. Finally, identification of all the victims were established by application of standard forensic practices together with odontology investigations.
\end{abstract}

\section{Introduction}

Road trauma is reckoned a significant cause of mortality and property destruction in Sri Lanka and many other countries [1]. According to annual police report, from January to June 2006 there had been 18,168 road traffic accidents including 1044 fatal incidents compared to 22,954 accidents in the first half of the year 2005. There were 1096 deaths including 327 pedestrians, 218 motorcyclists and 190 occupants of the vehicles, during that period. The srilankan law requires that all road deaths to be inquired by either inquirers into sudden death or magistrates, and invariably associated with an autopsy examination. The main objectives of autopsy examination are identification of the victims, determination of injury patterns in relation to the circumstances, establishment of the main reason for death and investigation of alcohol and drug abuse by the victims as for framing charges against the responsible parties, also to work out sustainable preventive measures. Here, we present a case of bus-truck collision which resulted in 42 injured persons and 19 deaths, whose bodies were extensively burnt due to post impact fire.

\section{Background Information}

A bus running from Galle to Colombo, with about 70 passengers on board collided against the container loaded with bottles of beer on the 2007/4/10 around $6.30 \mathrm{am}$. The incident took place on Galle-Colombo main road, at a sharp curve which has an inclination of 70 degrees, where one side of the road slopes down. The two vehicles that were moving on opposite directions collided at the bend resulting overturning of the bus, obstructing the both exits. Passengers were entrapped inside the bus. Both vehicles were caught in post-crash fire immediately after the collision (Figure 1). Many neighboring people, who gathered around the scene couldn't help the victims due to extremely high temperatures due to fire. A fire brigade arrived and extinguished the fire in one and half hours of the incident.

\section{Brief Description on Management of Injured Persons}

42 injured persons were admitted to a local hospital and then transferred to the Teaching Hospital Karapitiya in Galle. There were 3 patients with burns, 13 with fractures and others with minor injuries and had been managed at the surgical units. Two victims succumbed to their injuries while being treated in the hospital. The present study is dealing with pathological aspect of the issue and does not study into clinical cases in detail.

\section{Deceased Persons}

There were19 deaths, including both drivers. All these bodies were extensively burnt, and beyond visual recognition (Figure 2). The dead bodies were transferred to the medico-legal morgue at Karapitiya Teaching Hospital for further investigations.

\section{Our Approach to Medico-Legal Investigation}

The detailed statements from relatives and other connected parties were recorded by the Police. An electronic data bank was setup and antemortem data from all available sources were collected

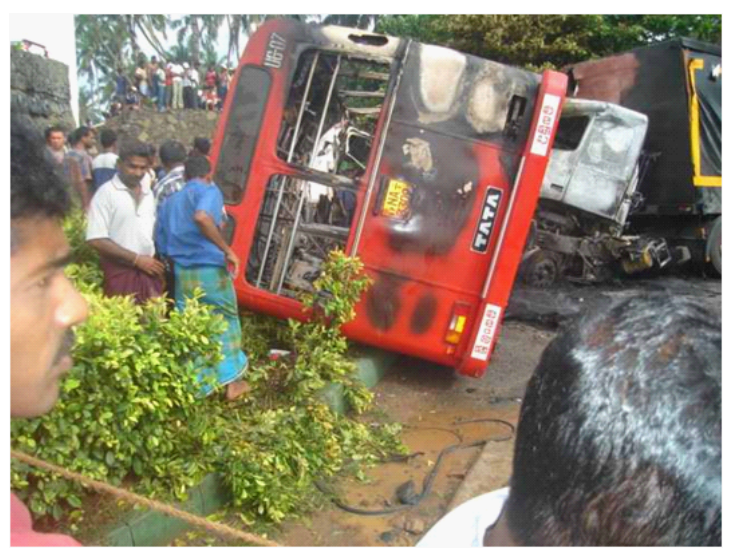

Figure 1: Partly burnt bus and truck.

${ }^{*}$ Corresponding author: Rohan Ruwanpura, Consultant Judicial Medical Officer Teaching Hospital, Karapitiya, Galle, Sri Lanka, E-mail: rohanr@mobitelnet.Ik

Received November 21, 2011; Accepted February 16, 2012; Published February 18, 2012

Citation: Ruwanpura R, Vidanapathirana M, Ranasinghe S, Hettiarachchi M Warushahennadi J, et al. (2012) Identification of Severely Burnt Bodies Due to Post Collision Fire: Bus - Truck Collision at Induruwa, Southern Sri Lanka. J Forensic Res 3:143. doi:10.4172/2157-7145.1000143

Copyright: (C) 2012 Ruwanpura R, et al. This is an open-access article distributed under the terms of the Creative Commons Attribution License, which permits unrestricted use, distribution, and reproduction in any medium, provided the original author and source are credited. 


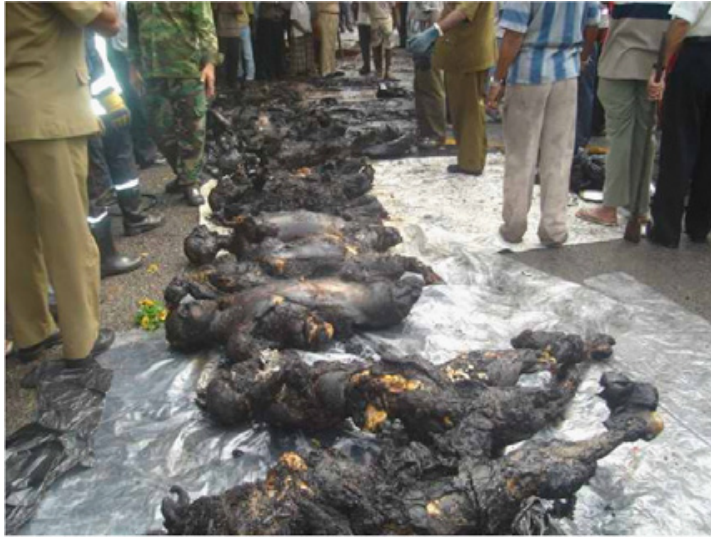

Figure 2: Bodies of victims at the scene.

in accordance with an INTERPOL protocol [2]. The bodies were kept on the floor, under the supervision of the Scene of Crime Officers of the Sri Lankan police and relatives were instructed to identify them by external appearance, clothing and personal effects, where provisional identification of 11 persons has been made. The provisional identity of these eleven bodies was further confirmed by comparison of data obtained in INTERPOL protocol.

It has been decided to conduct thorough autopsy examinations on the same day in order to overcome development of artifacts due to decomposition and facilitate the release of dead bodies to the relatives as soon as possible. Autopsy was combined with full body x-rays, anthropological assessments, recording of dental data, recording of personal effects and collection of tissue samples for DNA and other investigations. The three step identification process comprised of;

1) Provisional identification of victims according to data collected under INTERPOL system.

2) Sex and Age determination by anthropological methods during autopsy.

3) Specific identity of individuals by odontological data, personal effects and circumstantial evidence.

\section{Results}

Seven dead bodies that were recognized by the relatives from personal effects such as ear studs, mobile phones, parts of clothing, were further confirmed by (Figure 7) anthropological and dental characteristics, and released on the same night. An identity of a 28 year old man [V -6], a soldier, has been confirmed by characteristic familial positional malformation of upper incisor tooth (Figure 3), as his sister who presented for identification of the deceased, also has a similar congenital defect. Driver of the container truck was located at his seat and identity was confirmed by anthropological data. The driver of the bus, who suffered chest injuries and second degree burns has been treated in the hospital for three days before succumbed to his injuries.

The gender and the age of sixteen corpses were established by dental features and anthropological data (Figure 4,5), which exactly matched with the antemortem details recorded in our database. Finally, a body of a female child [V 19] was recognized by exclusion.

The autopsy revealed soot particles in deep bronchial divisions in 16 victims. Head injuries were observed in 2 cases (Figure 6), blunt abdominal and thoracic injuries were seen in 3 cases. Other external injuries and fractures were probably distorted by severe burns. Thus, the cause of death certificates was issued accordingly.

\section{Discussion}

The main medico-legal issues associated with this case include Management of injured persons, identification of deceased, determination of the cause of death, compensation [3] including immediate cash payment as funeral expenses from the Ministry of Disaster Management and payments from the insurance companies, dealing with public and political pressure, and elimination of fraudulent claims.

As in any mass casualty incident, evacuation of injured persons from the dangerous environment is one of the priorities of management [4]. Unfortunately, in present incident, many passengers entrapped inside the bus were unable to escape as it turned over onto the right side, obstructing both main entrances. According to the police about 45 passengers managed to come out through the windows, but none attempted to open the emergency exit. Furthermore, both vehicles were caught in fire in seconds after the incident, preventing outsiders from assisting passengers. It appeared that many passengers could have been incapacitated by injuries and shock due to the collision, diminishing their volitional capacity to escape. This is further confirmed by the presence of soot particles in deep bronchi in all the victims, viz, they were alive at the time of onset of the fire [5]. The majority of victims were either above 30 or below 12 years in age. The external injuries on majority victims were not revealed due to destruction of the surfaces by severe burns of the skin.

As it took about one and half hours for the fire fighters to arrive at the scene and extinguish it, the bodies of 19 victims were recovered in a state of severe burns and were beyond the visual recognition. In many jurisdictions, there are four legally admissible methodologies of identification 1-visual recognition, 2 - dental identification, 3 fingerprint comparison and 4 - DNA typing [6]. In this context, the collection of antemortem details from relatives found to be particularly useful in grouping victims according to gender and the age which

\begin{tabular}{|c|c|c|c|c|c|c|c|c|c|c|c|c|c|c|c|c|c|c|c|}
\hline Victims & 1 & 2 & 3 & 4 & 5 & 6 & 7 & 8 & 9 & 10 & 11 & 12 & 13 & 14 & 15 & 16 & 17 & 18 & 19 \\
\hline Sex & M & M & M & M & M & M & M & M & M & M & M & M & FM & FM & FM & FM & FM & FM & FM \\
\hline Age [Years] & 34 & 48 & 44 & 64 & 30 & 28 & 52 & 54 & 19 & 38 & 48 & 10 & 56 & 42 & 32 & 36 & 29 & 21 & 8 \\
\hline $\begin{array}{l}\text { Identity by } \\
\text { Interpol Protocol }\end{array}$ & + & + & + & + & + & + & + & + & + & + & + & + & + & + & + & + & + & + & \\
\hline $\begin{array}{l}\text { Dental age and other } \\
\text { characteristics }\end{array}$ & + & + & & + & + & + & & & + & + & + & + & & + & & + & + & + & + \\
\hline Anthropology & + & & + & & + & + & & + & + & & & + & & & + & & + & + & + \\
\hline Personal effects & & + & & + & + & & + & & & & & & + & & + & + & & & \\
\hline
\end{tabular}

Table 1: Summary of results. 


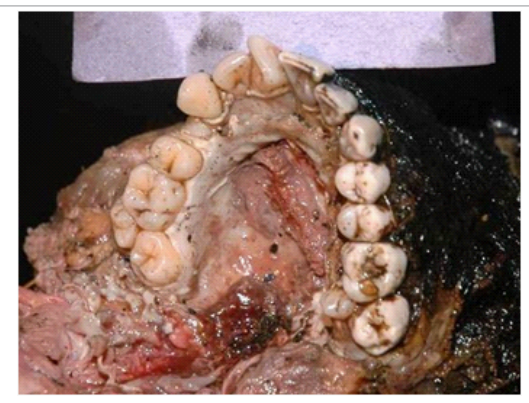

Figure 3: Congenital positional abnormality of right first upper incisor.

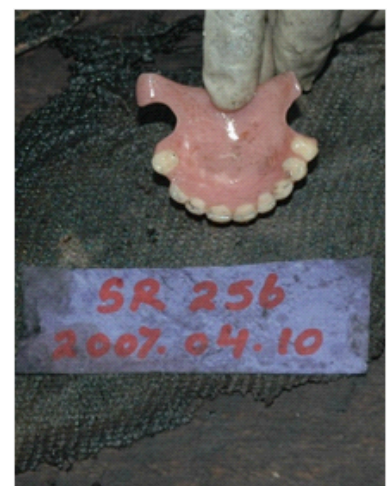

Figure 4: A denture: recently manufactured and recognized by spouse of the victim.

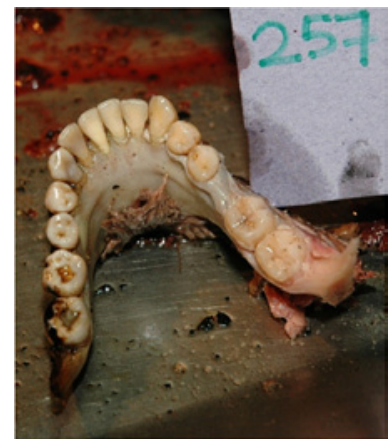

Figure 5: A lower jaw with dental caries and other features.

helped us to recognize two fraudulent claims for compensation. Use of INTERPOL protocol found to be convenient for feeding data into the electronic system. The DNA and dental identification are methods of choice in a situation of this nature [7]. In spite of that the proper dental records are not regularly maintained in Sri Lanka, the relatives of the deceased persons were able to provide many significant dental features of the victims. General recognition of victims' bodies was supported by personal effects, and dental data made it possible for us to identify all19 victims on positive findings, leaving expensive DNA tests aside, showing an advantage of simple, systematic application of conventional identification techniques.

In conclusion, the medico legal issues of identification and the establishment of causes of death were satisfactorily done by applying general principles of medico-legal practice at no extra cost. The importance of collective effort of police, clinicians, fire fighters,

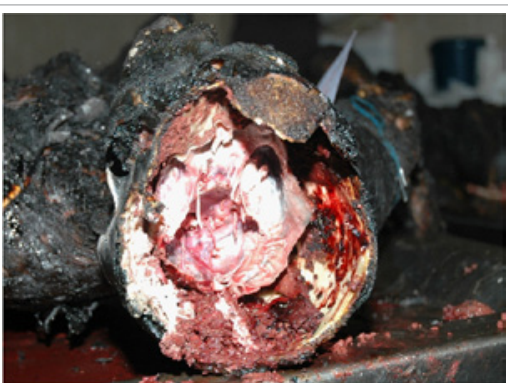

Figure 6: Skull fracture with remnants of antemortem subdural haemorrhage and post mortem extraduaral haematoma.

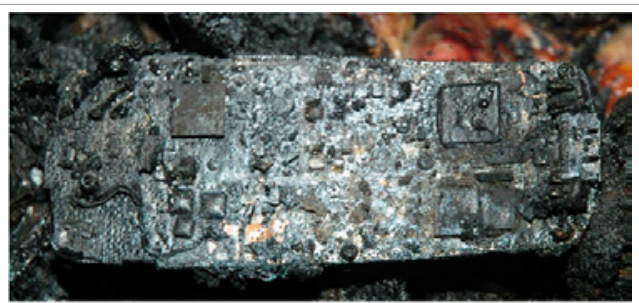

Figure 7: A burnt base of a mobile phone the type of which was established.

volunteers and forensic pathologists and odontologists in management of mass casualty incident is stressed.

\section{References}

1. Gordon WT (1992) Road trauma prevention: Perspectives. World J Surg 16 370-373.

2. Disaster victim identification. Available at www.Interpol.int/Public/DisaterVictim Default.asp Date Accessed 14 January 2012.

3. Ghosh DK (1998) Role of forensic pathologist in mass disaster management Journal of Indian academy of forensic medicine 20: 72-73.

4. Management of mass disaster.

5. Valová M, Königová R, BrozŠ L, Vajtr D (2004) Early and late complications of inhalation injury. Acta Chir Plast 44: 51-54

6. Stimson PG, Mertz CA (1997) Forensic Dentistry, CRC press, Florida186-4.

7. Wood FM (2005) Management of burn victims-a mass disaster situation. Nihon Nessho Gakkai Sokai, Gakujutsu Shukai Puroguramu, Shorokushu 31: 42. 